\title{
Hydrothermal Synthesis of SBA-15 Using Sodium Silicate Derived from Coal Gangue
}

\author{
Jing Wang, Li Fang, Fangqin Cheng, Xiaofang Duan, and Rongming Chen \\ State Environmental Protection Key Laboratory of Efficient Utilization Technology of Coal Waste Resources, \\ Institute of Resource and Environment, Shanxi University, Taiyuan 030006, China
}

Correspondence should be addressed to Fangqin Cheng; cfangqin@sxu.edu.cn

Received 30 December 2012; Accepted 20 March 2013

Academic Editor: Yongcheng Jin

Copyright (c) 2013 Jing Wang et al. This is an open access article distributed under the Creative Commons Attribution License, which permits unrestricted use, distribution, and reproduction in any medium, provided the original work is properly cited.

Well-ordered SBA-15 was prepared with a hydrothermal route by sodium silicate derived from coal gangue. The as-prepared sample was analyzed by SAXRD, BET, TEM, and SEM, respectively. The results indicate that at a low hydrothermal temperature of $100^{\circ} \mathrm{C}$ the well-ordered mesoporous SBA-15 could be synthesized. The surface area, pore volume, and pore size of the sample are $552 \mathrm{~m} / \mathrm{g}$, $0.54 \mathrm{~cm}^{3} / \mathrm{g}$, and $7.0 \mathrm{~nm}$, respectively. It is suggested that coal gangue could be used in obtaining an $\mathrm{Si}$ source to prepare mesoporous materials, such as SBA-15.

\section{Introduction}

The coal production of China now ranks top in the world, and so there is the biggest coal gangue yield. Despite being used as alternative material in road, pavement, embankment, foundation, or building construction, and so forth $[1,2]$, most of the coal gangue is still open-air stack-stored near by the coal mines and occupies vast pieces of land leading to a series of environmental problems, such as pollutions of air, water, and soil induced by the spontaneous combustion and eluviations. This became one of the highly important factors in restricting the economic sustainable development and the ecological civilization construction of the coal production area. Nevertheless, the coal-based energy structure could not change in the short term and thus the comprehensive utilization of coal gangue with high added value and minimal environmental impact turns into a big challenge.

Mesoporous silica has attracted much attention over the past decades due to not only their uniform mesostructures and excellent properties but also their amazing potential applications [3-6]. SBA-15 is one of the most extensively studied and applied example which could be prepared with highly reproducible pathways using commercial availability surfactants (such as P123), silica precursors, and facile [7, 8].
In addition, small particle size and rod-like morphology of SBA-15 received increasing interest for their fast adsorption and mass transfer [9]. Previously, most of the SBA-15 was obtained using expensive TEOS as silica precursors; thus efforts have been made to use inexpensive sodium silicate as a silica source [10-12]. In some earlier reports, the sodium silicate from fly ash has been used in the synthesis of SBA-15 [13-16], giving a good example for making good use of waste and reducing material costs.

It is well known that coal gangue mainly consists of about $20 \mathrm{wt} . \%$ carbon, $25 \mathrm{wt} . \%$ alumina, and $48 \mathrm{wt} . \%$ silica, and so sodium silicate could be made from the waste [17-20]. However, in the literatures, the SBA-15 synthesized using sodium silicate from coal gangue as a silica source was not reported.

Here we synthesized well-ordered SBA-15 successfully using sodium silicate derived from coal gangue under lowtemperature hydrothermal condition to gain insight into the possibility of high-quality application of coal gangue.

\section{Experimental}

2.1. Materials. Coal gangue was donated by Lu'an Group (Shanxi, China) and used after being grinded to particles 
about $200 \mu \mathrm{m}$ in size. Hydrochloric acid ( $\mathrm{HCl}, 36 \%)$, sodium carbonate $\left(\mathrm{Na}_{2} \mathrm{CO}_{3}, 98 \%\right)$, sodium silicate $\left(\mathrm{Na}_{2} \mathrm{Si}_{3} \mathrm{O}_{7}\right.$, with 25 wt. $\% \mathrm{SiO}_{2}$ and 14 wt. $\% \mathrm{NaOH}$ ), and acetic acid (HAc) were purchased from SCR. The triblock copolymer $\mathrm{EO}_{20} \mathrm{PO}_{70} \mathrm{EO}_{20}$ (P123) was from Aldrich.

\subsection{The Preparation of Sodium Silicate from Coal Gangue.} Raw coal gangue was ground to powder with a mesh size of less than $1000 \mu \mathrm{m}$ using a mechanism grinder. The powder was calcined at $750^{\circ} \mathrm{C}$ for $2 \mathrm{~h}$ and then leached with $36 \% \mathrm{HCl}$ at $40^{\circ} \mathrm{C}$ until no weight loss being observed. By this way, most aluminum oxide, ferric oxide, and other impurities were removed, which could be used to produce polyaluminum chloride employed as waste water purifier. The remained mixture was collected as silica slag. After that, soluble sodium silicate was prepared with the silica slag by a new developed low-temperature comelting method. Silica slag was mixed with $\mathrm{Na}_{2} \mathrm{CO}_{3}$ at a 3:2 weight ratio and grinded for $1 \mathrm{~h}$ using a ball mill (about $5-10 \mu \mathrm{m}$ ). The mixture was calcined at a heating rate of $5^{\circ} \mathrm{C} / \mathrm{min}$ up to $850^{\circ} \mathrm{C}$ for $3 \mathrm{~h}$ in a muffle furnace. Afterwards, the liquid melt was quenched in boiled water to get small fragments and transferred into a highpressure reactor filled with water and heated up to $150^{\circ} \mathrm{C}$ for $5 \mathrm{~h}$. The obtained liquid mixture was filtered and then the asprepared sodium silicate solution was obtained. The contents of the coal gangue, the silica slag, and the as-prepared sodium silicate are listed in Table 1. It can be seen that there is over $95 \% \mathrm{SiO}_{2}$ in the as-prepared sodium silicate.

2.3. Preparation of $S B A-15$. The mesoporous silica was prepared using a slightly modified hydrothermal route [10]. P123 $2 \mathrm{~g}$ was dissolved in $48 \mathrm{~mL}$ of $2 \mathrm{M} \mathrm{HCl}$, in which $3.1 \mathrm{~g}$ HAc was added and stirred for $4 \mathrm{~h}$ to obtain solution A. $25 \mathrm{~mL}$ of the as-prepared sodium silicate solution was stirred for $10 \mathrm{~min}$ at room temperature as solution B. At $40^{\circ} \mathrm{C}$, solution B was added into solution $\mathrm{A}$ dropwise under vigorous stirring. The mixture was stirred for $10 \mathrm{~min}$ at $40^{\circ} \mathrm{C}$ and then was kept motionless at room temperature for $12 \mathrm{~h}$. The sediment was filtrated and washed with deionized water several times until $\mathrm{Na}^{+}$could not be detected in the washing liquor. Then, $20 \mathrm{~g}$ of deionized water was added in the washed sediment. The $\mathrm{pH}$ of the obtained mixture was adjusted to 1.7 with $2 \mathrm{M} \mathrm{HCl}$ before being transferred into a hydrothermal reaction kettle. After the hydrothermal reaction at $100^{\circ} \mathrm{C}$ or $200^{\circ} \mathrm{C}$ for $24 \mathrm{~h}$, the collected samples were filtered, washed, dried in air, and then sintered at $650^{\circ} \mathrm{C}$ for $5 \mathrm{~h}$ to get as-prepared SBA-15 (Sslag). For comparison, pure SBA-15 samples were prepared using commercially available (pure) sodium silicate as a silica source at $100^{\circ} \mathrm{C}$ and $200^{\circ} \mathrm{C}$, which were denoted as S-100 and S-200.

2.4. Characterization. Small-angle X-ray diffraction (SAXRD) analysis of the as-prepared SBA-15 samples was carried out at room temperature using a Rigaku D/MAX-RB diffractometer with $\mathrm{Cu} \mathrm{K} \alpha$ radiation with graphite crystal monochromized. Nitrogen adsorption/desorption was performed at $77 \mathrm{~K}$ using in a Micromeritics ASAP2010 Sorptometer. The surface area and the pore sizes were
TABLE 1: The components of coal gangue, silica slag, and prepared sodium silicate.

\begin{tabular}{lccccc}
\hline Components (wt.\%) & $\mathrm{SiO}_{2}$ & $\mathrm{Al}_{2} \mathrm{O}_{3}$ & $\mathrm{Fe}_{2} \mathrm{O}_{3}$ & $\mathrm{~K}_{2} \mathrm{O}$ & $\mathrm{TiO}_{2}$ \\
\hline Coal gangue & 32.35 & 57.79 & 3.37 & 2.77 & 1.15 \\
Silica slag & 80.49 & 8.37 & 0.53 & 1.14 & 2.31 \\
Soluble sodium silicate & 95.21 & 0.07 & - & 4.61 & - \\
\hline
\end{tabular}

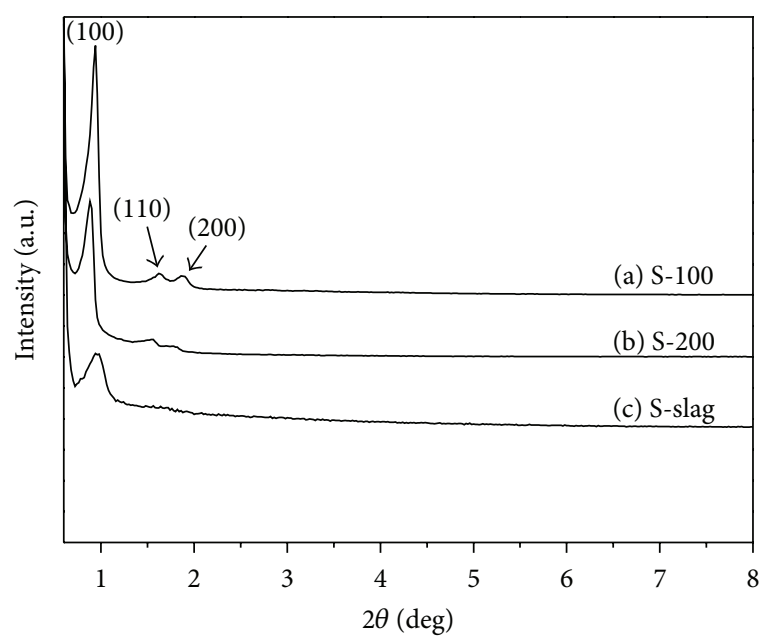

FIGURE 1: XRD patterns of the SBA-15 samples ((a) S-100, (b) S-200, and (c) S-slag $\left(100^{\circ} \mathrm{C}\right)$ ).

obtained from nitrogen adsorption isotherms by BrunauerEmmett-Teller (BET) and Barrett-Joyner-Halenda (BJH) methods, respectively. Transmission electron microscopy (TEM) measurements were taken on a JEOL JEM-2100F field emission electron microscope with an acceleration voltage of $200 \mathrm{kV}$. Scanning electron microscopy (SEM) images were obtained on a Hitachi S-4800 electron microscope.

\section{Results and Discussion}

3.1. Small-Angle X-ray Diffraction. Figure 1 shows the XRD patterns of the SBA-15 samples, S-100, S-200, and S-slag, after calcinations at $650^{\circ} \mathrm{C}$ for $5 \mathrm{~h}$. The peaks of curve (a) of S-100 in Figure 1 show a characteristic intense (100) and two higher-order (110) and (200) reflections at $2 \theta$ values of $0.94^{\circ}, 1.60^{\circ}$, and $1.87^{\circ}$, respectively, which are characteristics of SBA-15 $p 6 \mathrm{~mm}$ hexagonal symmetry. In comparison with the XRD patterns of SBA- 15 prepared at $200^{\circ} \mathrm{C}$ showed as curve (b) in Figure 1, the diffractions of S-100 shift to higher $2 \theta$ degrees indicating small pore volume formed at lower hydrothermal temperature. However, significant enhancement in peak intensity can be observed when hydrothermal temperature decreased from $200^{\circ} \mathrm{C}$ to $100^{\circ} \mathrm{C}$, indicating that the sample is highly long-range ordered with hexagonal symmetry [10]. The peak of curve (c) in Figure 1 at $0.96^{\circ}$ gives the confirmation of typical SBA-15 structure in S-slag. The other two peaks assigned to the (110) and (200) planes do not appear in curve (c), showing a weak long-range order in the sample. This may be explained by weak long-range ordered 


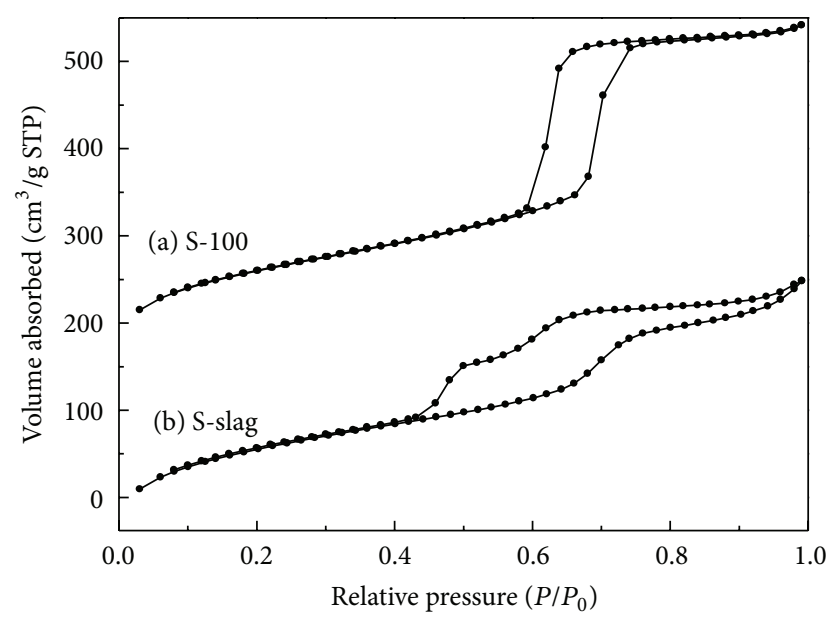

FIGURE 2: $\mathrm{N}_{2}$ adsorption isotherms of (a) S-100 and (b) S-slag.

TABLE 2: Textural parameters of the samples.

\begin{tabular}{lccc}
\hline Sample & $S_{\mathrm{BET}}\left(\mathrm{m}^{2} / \mathrm{g}\right)$ & $V_{p}\left(\mathrm{~cm}^{3} / \mathrm{g}\right)$ & $d_{p}(\mathrm{~nm})$ \\
\hline S-100 & 567 & 0.68 & 7.2 \\
S-slag & 552 & 0.54 & 7.0 \\
\hline
\end{tabular}

$S_{\mathrm{BET}}$ : specific surface area; $V_{p}$ : total pore volume, and $d_{p}$ : pore diameter.

crystalline formation of mesoporous silica due to lower silica content in reactant solution [13, 14]. In addition, the trace impurities introduced from S-lag, $\mathrm{Cl}^{-}$anions, and $\mathrm{SO}_{3}{ }^{2-}$ anions, for example, may also influence the formation of longrange ordered SBA-15. Since the existence of $\mathrm{Cl}^{-}$and $\mathrm{SO}_{3}{ }^{2-}$ anions may affect the micelle structures during the sol-gel process, the influence mechanism will be further investigated in detail.

3.2. Nitrogen Adsorption/Desorption. The $\mathrm{N}_{2}$ adsorption/ desorption isotherms and corresponding pore size distribution of the samples are shown in Figures 2 and 3, respectively. Curve (a) in Figure 2 (S-100) exhibits a typicaltype IV isotherm [13] and a steep capillary condensation step occurred at a relative pressure $\left(P / P_{0}\right)$ ranging from 0.59 to 0.76 . Hysteresis appearing in the multilayer range of physisorption isotherms indicates capillary condensation in mesoporous structures. The curve exhibits $\mathrm{H} 1$ hysteresis loops; two branches are almost vertical and nearly parallel. According to the classification of IUPAC [21], this type is associated with porous materials consisting of agglomerates or compacts of approximately uniform rods-like particles in fairly regular array, therefore showing narrow pore size distribution (curve (a) in Figure 3). The surface area, pore volume, and pore size are $567 \mathrm{~m}^{2} / \mathrm{g}, 0.68 \mathrm{~cm}^{3} / \mathrm{g}$, and $7.2 \mathrm{~nm}$, respectively (seen in Table 2).

According to curve (b) in Figure 2, it can be seen that the isotherm of S-slag is analogous to that of S-100, but it shows a less steep capillary condensation step in a wider $P / P_{0}$ range from 0.43 to 1 , indicating low pressure needed for the capillary condensation due to small pores formation and wide distribution of pore sizes (curve (b) in Figure 3). In addition, the hysteretic loop belongs to type H4, exhibiting that the stacking pores are slit-shaped tunnels which are generally induced by the irregular morphology of mesoporous silica. Clearly, the result of $\mathrm{N}_{2}$ adsorption/desorption isotherms is consistent with the result of XRD analysis. This was also in agreement with the conclusion drawn by Wang et al., who claimed that impurities from fly ash may affect mesoporous construction [22]. By Brunauer-Emmett-Teller (BET) and Barrett-Joyner-Halenda (BJH) methods, the surface area, pore volume, and pore size of the SBA-15 samples were calculated and listed in Table 2. The surface area, pore volume, and pore size of the S-slag are $552 \mathrm{~m}^{2} / \mathrm{g}, 0.54 \mathrm{~cm}^{3} / \mathrm{g}$, and $7.0 \mathrm{~nm}$, respectively.

3.3. TEM and SEM. TEM images of S-100 and S-slag are shown in Figure 4. It can be found that both S-100 and S-slag are analogous to each other exhibiting well-ordered mesoporous materials arrayed along (100) and (110) directions as 2-dimensional hexagonal structures, in agreement with the XRD results.

The pore sizes of the particles of S-100 and S-slag were measured directly along the (110) directions in the TEM images. The results are $6.62 \mu \mathrm{m}$ and $7.01 \mu \mathrm{m}$ (shown in Figures $4(\mathrm{~b})$ and $4(\mathrm{~d})$ ), respectively. The measured size of S-100 is smaller than the average pore size obtained from BET analysis, which could be explained by the difference between the methodologies.

SEM images of S-100 and S-slag are illustrated in Figure 5. It is clearly observed from Figure 5(a) that the particles of S-100 show both worm-like and rod-like morphology and aggregate together with a particle size less than $1 \mu \mathrm{m}$, which is very similar to an earlier report [9]. On the contrary, Figure 5(b) shows that several spherical particles with diameters less than $2-3 \mu \mathrm{m}$ together with some small irregularshape particles are observed in the S-slag sample, indicating poor long-range ordered structures.

\section{Conclusion}

Sodium silicates derived from coal gangue was used as a silica source for SBA-15 synthesis via a low-temperature hydrothermal route. The characteristic of an SBA-15 $p 6 \mathrm{~mm}$ hexagonal symmetry structure in the as-prepared sample, Sslag, was confirmed by SAXRD, $\mathrm{N}_{2}$ adsorption/desorption, and TEM. A weak long-range ordered crystalline formation of the mesoporous silica has been found in the sample due to lower silica content in reactant solution and the trace impurities introduced from S-slag. The results suggest that sodium silicate derived from coal gangue is a promising candidate for preparing mesoporous silica, such as SBA-15.

\section{Acknowledgments}

This work was financially supported by the International Scientific and Technological Cooperation of China (2011DFA90830), the National Hi-Tech Research and Development Program of China (863 Program, 


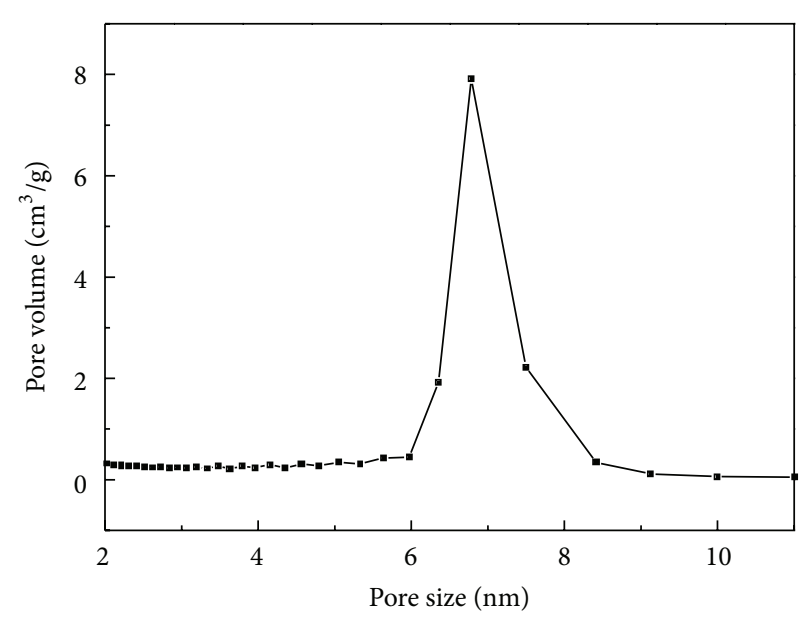

(a) S-100

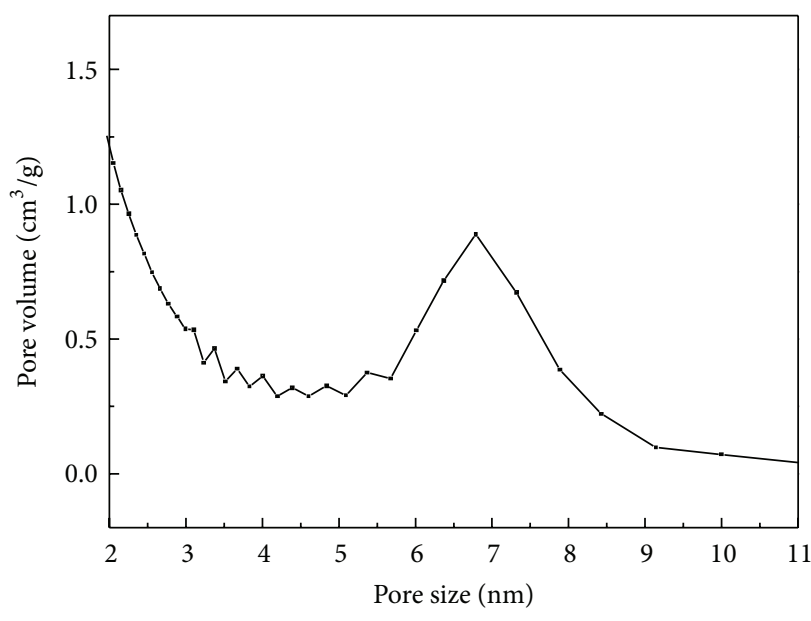

(b) S-slag

FIgure 3: Pore size distribution of (a) S-100 and (b) S-slag.

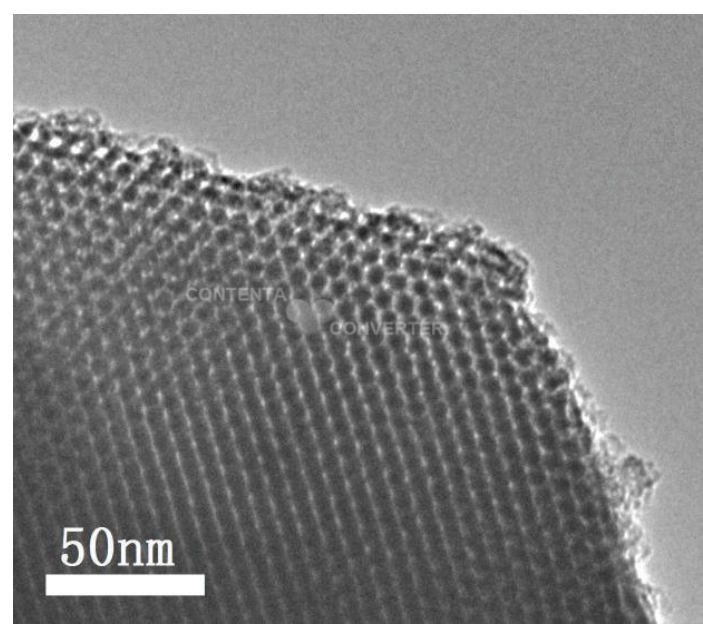

(a)

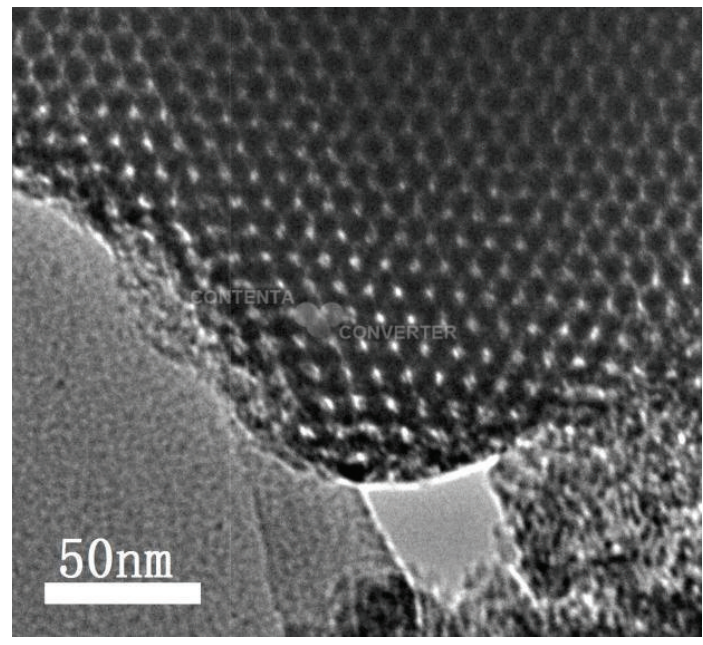

(c)

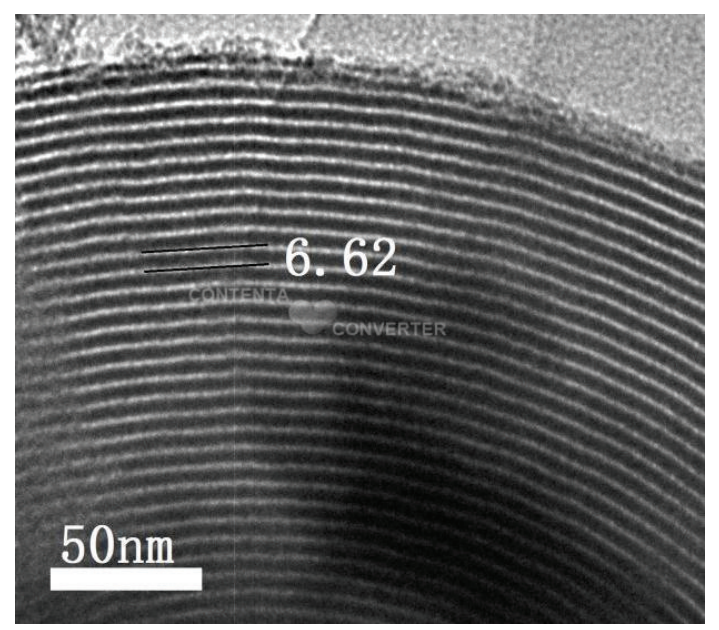

(b)

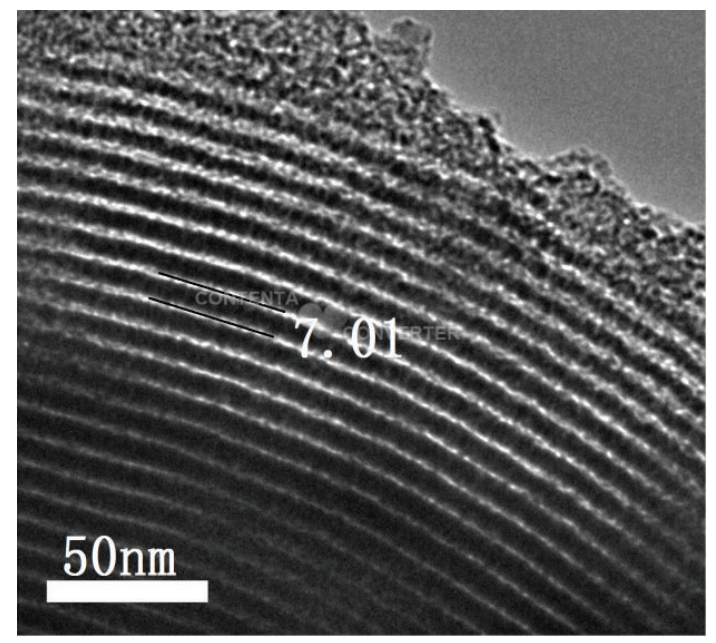

(d)

FIGURE 4: TEM images of S-100 viewed along (100) (a) and (110) (b) directions, and S-slag viewed along (100) (c) and (110) (d) directions. 


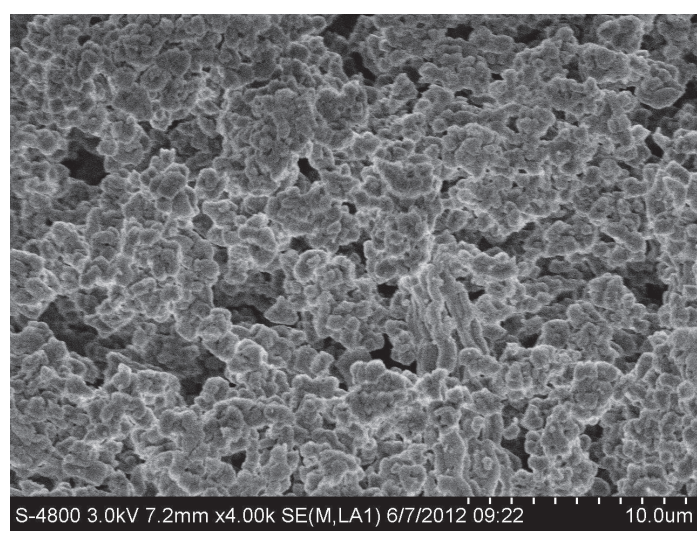

(a)

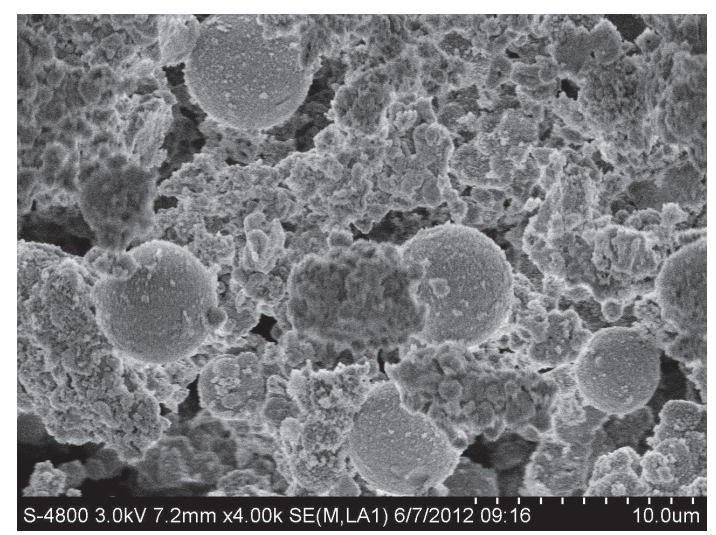

(b)

FIGURE 5: SEM images of (a) S-100 and (b) S-slag.

2011AA06A103). The authors are thankful to Xuming Wang, the professor at the Department of Metallurgical Engineering, College of Mines and Earth Sciences, University of Utah, Salt Lake City, UT, USA, for direction.

\section{References}

[1] G.-1. Yang, R.-S. Yang, Q. Tong, and C. Huo, "Coalmine green mining with Gangue backfilling technique," Procedia Environmental Sciences, vol. 10, pp. 1205-1209, 2011.

[2] N. Zhang, H. Sun, X. Liu, and J. Zhang, "Early-age characteristics of red mud-coal gangue cementitious material," Journal of Hazardous Materials, vol. 167, no. 1-3, pp. 927-932, 2009.

[3] H. Yang, R. Xu, X. Xue, F. Li, and G. Li, "Hybrid surfactanttemplated mesoporous silica formed in ethanol and its application for heavy metal removal," Journal of Hazardous Materials, vol. 152, no. 2, pp. 690-698, 2008.

[4] L. Yang, Y. Wang, G. Luo, and Y. Dai, "Preparation and functionalization of mesoporous silica spheres as packing materials for HPLC," Particuology, vol. 6, no. 3, pp. 143-148, 2008.

[5] R. Ishii, T. Itoh, T. Yokoyama et al., "On-chip encapsulation of lipase using mesoporous silica: a new route to enzyme microreactors," Materials Letters, vol. 63, no. 28, pp. 2445-2448, 2009.

[6] J. Fan, J. Lei, C. Yu, B. Tu, and D. Zhao, "Hard-templating synthesis of a novel rod-like nanoporous calcium phosphate bioceramics and their capacity as antibiotic carriers," Materials Chemistry and Physics, vol. 103, no. 2-3, pp. 489-493, 2007.

[7] L. Cao and M. Kruk, "Facile method to synthesize platelet SBA15 silica with highly ordered large mesopores," Journal of Colloid and Interface Science, vol. 361, no. 2, pp. 472-476, 2011.

[8] P. F. Fulvio, S. Pikus, and M. Jaroniec, "Short-time synthesis of SBA-15 using various silica sources," Journal of Colloid and Interface Science, vol. 287, no. 2, pp. 717-720, 2005.

[9] X. Pang and F. Tang, "Morphological control of mesoporous materials using inexpensive silica sources," Microporous and Mesoporous Materials, vol. 85, no. 1-2, pp. 1-6, 2005.

[10] D. Pan, L. Tan, K. Qian et al., "Synthesis of highly ordered and hydrothermally stable mesoporous materials using sodium silicate as a precursor," Materials Letters, vol. 64, no. 13, pp. 1543$1545,2010$.
[11] Y. Ding, G. Yin, X. Liao, Z. Huang, X. Chen, and Y. Yao, "Key role of sodium silicate modulus in synthesis of mesoporous silica SBA-15 rods with controllable lengths and diameters," Materials Letters, vol. 75, pp. 45-47, 2012.

[12] J. M. Kim and G. D. Stucky, "Synthesis of highly ordered mesoporous silica materials using sodium silicate and amphiphilic block copolymers," Chemical Communications, no. 13, pp. 11591160, 2000.

[13] G. Chandrasekar, K. S. You, J. W. Ahn, and W. S. Ahn, "Synthesis of hexagonal and cubic mesoporous silica using power plant bottom ash," Microporous and Mesoporous Materials, vol. 111, no. 1-3, pp. 455-462, 2008.

[14] M. Halina, S. Ramesh, M. A. Yarmo, and R. A. Kamarudin, "Non-hydrothermal synthesis of mesoporous materials using sodium silicate from coal fly ash," Materials Chemistry and Physics, vol. 101, no. 2-3, pp. 344-351, 2007.

[15] R. S. Blissett and N. A. Rowson, "A review of the multicomponent utilisation of coal fly ash," Fuel, vol. 97, pp. 1-23, 2012.

[16] I. Majchrzak-Kucęba and W. Nowak, "Characterization of MCM-41 mesoporous materials derived from polish fly ashes," International Journal of Mineral Processing, vol. 101, no. 1-4, pp. 100-111, 2011

[17] N. Wen, G. Renyou, and L. Cuiwei, "A study of producing light refractory bricks of mullite by using coal gangues as raw materials," Contributions to Geology and Mineral Resources Research, vol. 12, no. 4, pp. 79-86, 1997 (Chinese).

[18] Y. Yao and H. Sun, "A novel silica alumina-based backfill material composed of coal refuse and fly ash," Journal of Hazardous Materials, vol. 214, pp. 71-82, 2012.

[19] C.-L. Park, B.-G. Kim, and Y. Yu, "The regeneration of waste foundry sand and residue stabilization using coal refuse," Journal of Hazardous Materials, vol. 204, pp. 176-182, 2012.

[20] M. Yang, Z. Guo, and Y. Deng, "Preparation of $\mathrm{CaO}-\mathrm{Al}_{2} \mathrm{O}_{3}$ $\mathrm{SiO}_{2}$ glass ceramics from coal gangue," International Journal of Mineral Processing, vol. 103, pp. 112-115, 2012.

[21] K. S. W. Sing, D. H. Everett, R. A. W. Haul et al., "Physical and biophysical chemistry division commission on colloid and surface chemistry including catalysis," Pure and Applied Chemistry, vol. 57, no. 4, pp. 603-619, 1985. 
[22] W. Wang, W. Shan, H. Ru, and N. Wu, "A facile and versatile partitioned cooperative self-assembly process to prepare SBA15s with larger mesopores, high microporosity and tunable particle sizes," Journal of Materials Chemistry, vol. 21, no. 32, pp. 12059-12067, 2011. 

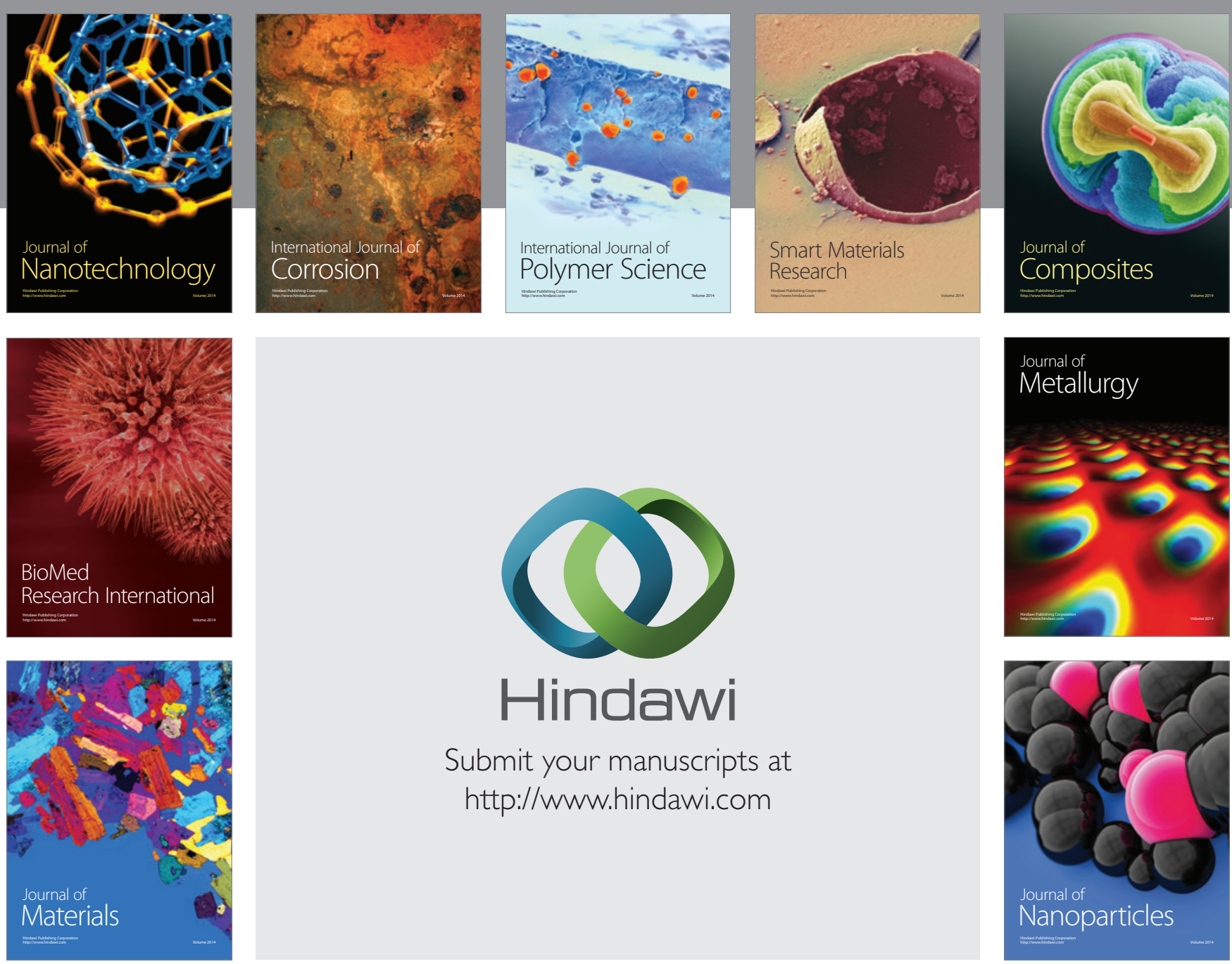

Submit your manuscripts at http://www.hindawi.com
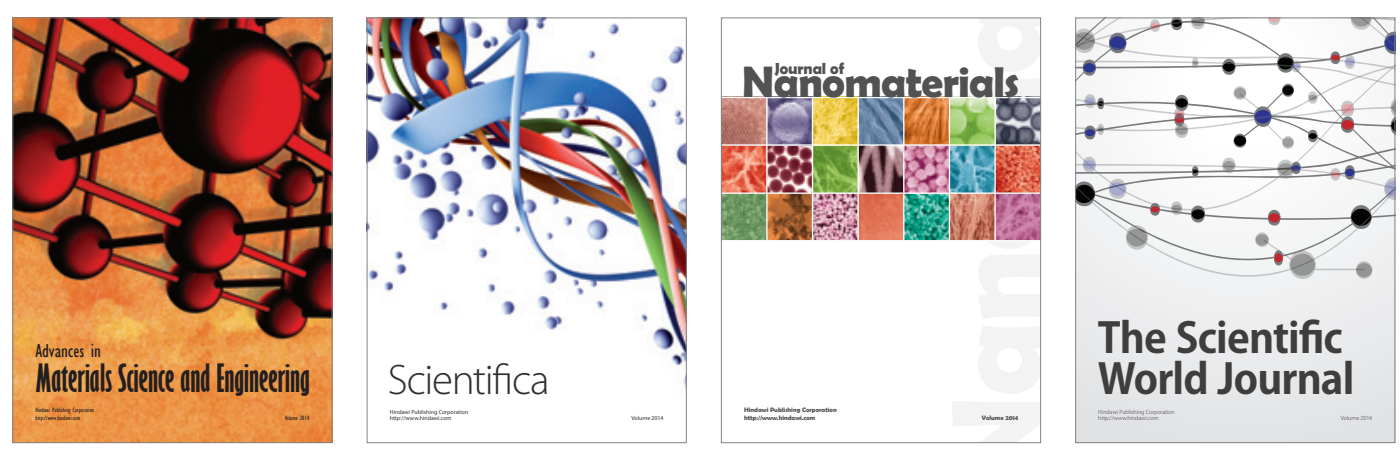

\section{The Scientific World Journal}
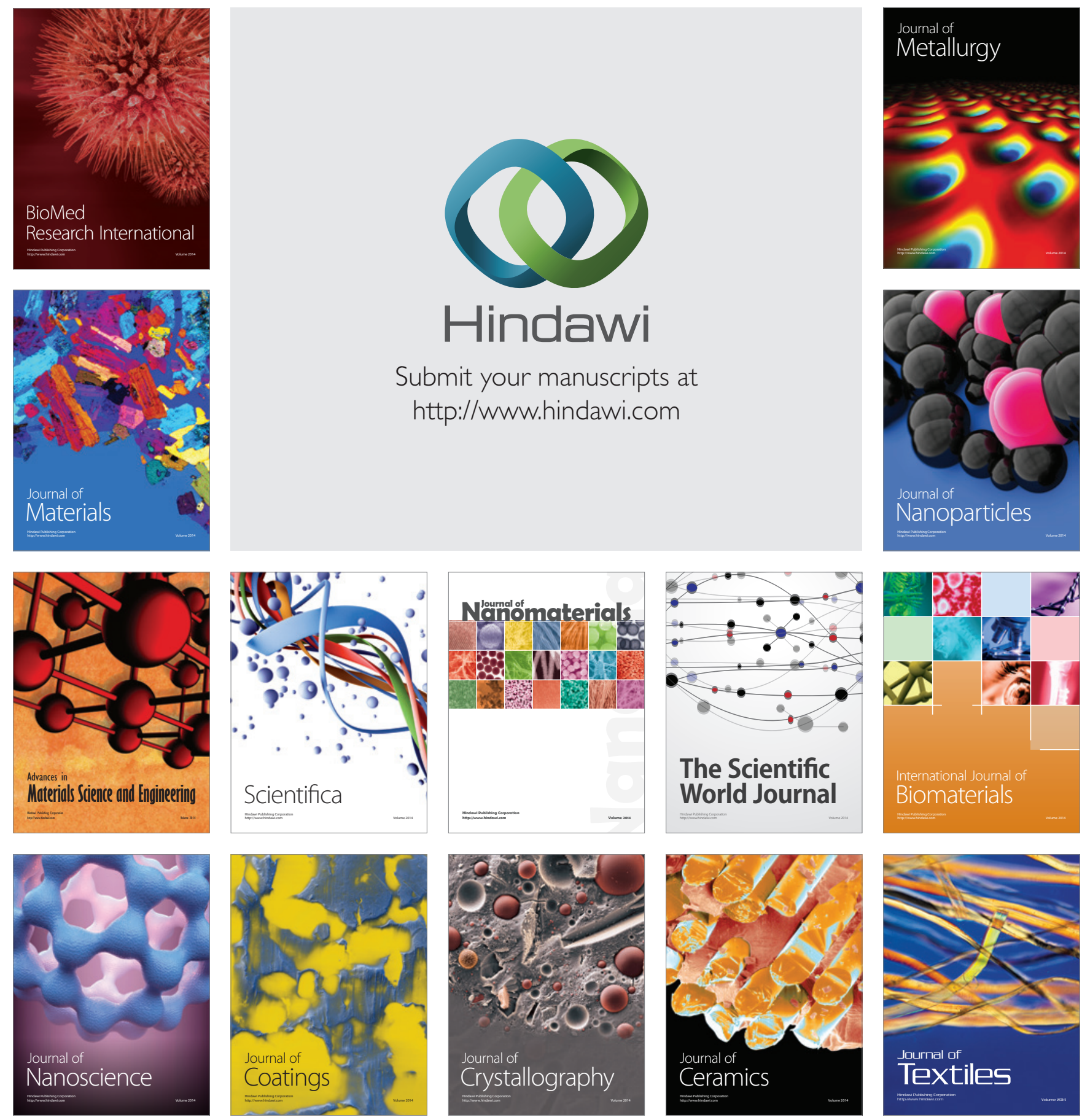